\title{
Status of Immunity Against the Hepatitis A Virus in Healthy Population: A Report From Southeastern Iran
}

\author{
Alireza Bakhshipour (iD ${ }^{1}$, Narjes Sargolzaie ${ }^{2}$ and Raheleh Rafaiee (iD) ${ }^{3, *}$ \\ ${ }^{1}$ Infectious Diseases and Tropical Medicine Research Center, Resistant Tuberculosis Institute, Zahedan University of Medical Sciences, Zahedan, Iran \\ ${ }^{2}$ Department of Community Medicine, Zahedan University of Medical Sciences, Zahedan, Iran \\ ${ }^{3}$ Department of Neuroscience, School of Advanced Technologies in Medicine, Mazandaran University of Medical Sciences, Sari, Iran \\ "Corresponding author: Department of Neuroscience, School of Advanced Technologies in Medicine, Mazandaran University of Medical Sciences, Sari, Iran. Email: \\ rachel.rafaie@yahoo.com
}

Received 2021 August 20; Accepted 2021 October 31.

\begin{abstract}
Background: Recently, epidemiological studies on hepatitis A virus (HAV) infection showed the seroprevalence has been changing due to changes in lifestyle. To the best of our knowledge, there have been no published data on the seropositivity of HAV in Zahedan, southeastern Iran.

Objectives: This study aimed to investigate the seroprevalence of HAV immunoglobulin G (IgG) antibody in Zahedan, southeastern Iran, to provide the required information for better planning in preventive strategies.

Methods: In this cross-sectional study, using the available sampling method, a total of 250 serum samples (18 years and above) in both the urban and rural areas of Zahedan were evaluated for anti-HAV IgG by enzyme-linked immunosorbent assay.

Results: Based on the results, it was observed that 228 out of 250 (91.2\%) serum samples were positive for HAV IgG antibody. Male gender, family size, parents' education, mother's occupation, and history of jaundice before the age of 12 years were associated with positive HAV antibody $(\mathrm{P}<0.001)$. The seroprevalence HAV rates were not statistically different between the residents of urban and rural regions.

Conclusions: The seropositivity of HAV is high in both the urban and rural areas of Zahedan, Iran. Therefore, the HAV vaccination of the general population is not necessary. It is recommended to monitor HAV seroprevalence in the general population to determine high-risk groups, including anti-HAV seronegative individuals, for HAV vaccination in the residents of the southeast border.
\end{abstract}

Keywords: Hepatitis A Virus, Prevalence, Seroepidemiological Study, Iran

\section{Background}

Among the picornaviruses family, hepatitis A virus (HAV) is a hepatotropic virus and is responsible for acute liver injury, especially in endemic areas (1). The World Health Organization (WHO) estimates that hepatitis A causes acute liver injury approximately 1.5 million per year worldwide (2), with an age-standardized mortality rate of about 0.26 per 100,000 individuals in 2017 (3). The epidemiology of this disease has changed over the last two decades in several developing countries $(4,5)$.

The HAV is transmitted almost exclusively through the fecal-oral route, contaminated food or water, and direct contact with an infectious individual are major routes of HAV worldwide (6). The prevalence of HAV is high in low socioeconomic regions, and poor hygiene and overcrowding are two main factors in these areas that resulted in the high prevalence of infection (7). Usually, HAV infection occurs in childhood, and lifelong immunity follows. With the improvement of sanitation and hygiene, the age of infection has shifted from childhood to adolescence or even adulthood. The HAV infection, similar to many other viral infections, when acquired in childhood, has a very benign course than when acquired in adulthood (8). Therefore, fulminant hepatic failure (deadly outcome) is extremely rare in children; however, a much more grave course is observed when the infection occurs at a later age (7).

Some studies showed that the prevalence of anti-HAV antibodies (accounting for remote infection and protection) in the general population ranges from 15 to $100 \%$ in various parts of the world (9-11). Therefore, vaccination against HAV is not recommended in regions where protection is high (infection limited to children) and inverse in communities where a significant percentage of adults have no immunity; the increased morbidity and mortality that occur with HAV infection justify vaccination (5). Immunization has been developed, and HAV infection could 
be prevented by vaccination, but has not yet been used widely (12).

To the best of our knowledge, there are valuable data on anti-HAV prevalence among the Iranian population; for example, in a study performed by Merat et al., the seroprevalence of HAV in Hormozgan, Golestan, and Tehran provinces, Iran, were 96, 99, and 85\%, respectively (13). In another Iranian study, Taghavi et al. reported that the antiHAV seroprevalence among the adult population in Fars province was $88.2 \%$ (14). The results of previous seroprevalence investigations in different regions in Iran suggested a hyperendemic pattern. Accordingly, routine vaccination against HAV is not currently recommended in Iran (15). During the last few decades, with improvement in sanitation and public health in Iran, the percentage of susceptible adults to HAV was probably increased (16). Such an increased susceptibility might justify the routine vaccination of children (17).

Up to now, international reports have categorized Iran as an intermediate endemic region for HAV. To date, recent studies and reports have shown that the seroprevalence of HAV in different provinces of Iran is decreasing, and now Iran can be categorized as a low endemic region for HAV infection $(18,19)$. The WHO also stated that each country should collect the data on the seropositivity of HAV in the general population to help policymakers in choosing appropriate preventive strategies (20).

In Zahedan, Iran, located near the Pakistan and Afghanistan borders, no data on the seroprevalence of HAV have been collected yet. Given the endemicity and high seroprevalence of HAV in Pakistan (9), numerous movements of individuals, especially the border residents across Iran-Pakistan borders, and an unusually large number of refugees from Afghanistan, and consequent health problems (21), this is important to investigate HAV seroprevalence in the southeast area of Iran to provide the required information for better planning in preventive strategies appropriately and can help decide on vaccination implementation policies timely, before raising morbidity and mortality of Iranian individuals.

\section{Objectives}

This study was performed to evaluate the seroprevalence of HAV in Zahedan, southeastern Iran.

\section{Methods}

In the present descriptive cross-sectional study, the data $(n=250)$ were collected from the general population of 18 years and above seeking laboratory services to undergo the necessary tests before marriage. The Research
Ethics Committee of Zahedan University of Medical Sciences approved the study. Eligible participants are selected by the availability sampling method. Written informed consent was received from the participants, which contained the well-explained process and objectives of the study. All the participants with a minimum age of 18 years were included when signing the informed consent. The individuals with a medical history of immunological disorders and immunosuppressive therapy were excluded. A paper-based anonymous questionnaire was administered. A trained research assistant, blind to study, interviewed and collected the data. The questions were asked regarding basic demographic characteristics, such as gender, age, household size, place of residence (i.e., urban or rural), history of jaundice before the age of 12 years, employment, and educational level of parents.

According to previous studies in Iran, the seroprevalence average of viral hepatitis A was $80 \%(13,22)$. With the consideration of this prevalence rate and based on $\mathrm{Z}_{\alpha / 2}=$ $1.96, P=0.8$, and $d=0.05$, the sample size was calculated at 245 participants, which in the present study was considered to be 250 participants. The sample size was measured using the following formula for sample calculation:

Sample size $=\frac{Z_{\frac{\alpha}{2}}^{2} \times P(1-P)}{d^{2}}$

The serum samples were collected, allocated numbers, and stored at $-70^{\circ} \mathrm{C}$ until tested for total anti-HAV immunoglobulin $\mathrm{G}(\operatorname{IgG})$ in the Laboratory of Zahedan Blood Transfusion Organization. Serum anti-HAV antibody was evaluated by enzyme-linked immunosorbent assay (DiaPro Diagnostic Bioprobes Srl, Milano, Italy). The results were reported as positive or negative. The positive cases of anti-HAV IgG antibody were considered immune to HAV through natural infection. On the other hand, negative cases for anti-HAV antibodies should be considered susceptible to HAV infection.

The results were analyzed using SPSS software (version 18.0; SPSS Inc., Chicago, IL, USA). Descriptive statistics (e.g., mean, percentage, standard deviation, and frequency) were calculated. In addition, the association between variables was measured using the $t$-test, chi-square test, and Fisher's exact test. The significance level was set at 0.05 .

\section{Results}

A total of 250 studied subjects (including 125 males and 125 females) within the age range of 18 - 63 years were enrolled in the study. Of the present sample, 228 participants (91.2\%) had IgG antibody against HAV, and 22 participants (8.8\%) were antibody negative. None of the sub- 
jects had a vaccination against HAV. The results of the chisquare test showed significant differences in the distribution of total anti-HAV frequency in terms of gender, number of family members, history of jaundice before the age of 12 years, parents' education, and mother's occupation. Table 1 shows the detailed data of the seroprevalence of HAV IgG antibody in the participants, according to gender, number of family members, place of residence, and history of jaundice. Table 2 shows the detailed data of the seroprevalence of anti-HAV IgG antibody according to the educational level and occupation of parents. No association was observed between the seropositivity of HAV with fathers' occupation and place of residence.

\section{Discussion}

The present study investigated the seroprevalence of HAV among the Iranian general population in Zahedan, southeastern Iran. There was an overall seroprevalence of $91.2 \%$ in the present sample, which is in line with the results of some similar studies. The hyperendemic pattern was reported by earlier published investigations in different provinces of Iran. A high prevalence rate of HAV infection was reported in some cities and provinces of Iran, such as $80.65 \%$ in Ahwaz (23), 79.2\% in Hamedan (24), 85\% in Tehran, 96\% in Hormozgan, 99\% in Golestan (13), 94.9\% in Qazvin (25), 70\% in Mashhad (26), 82\% in Sari (27), 88.6\% in Zabol (28), 90.8\% in Shahrekord (15), and 89.5\% in Yazd (29); however, HAV seroprevalence in Fars (66.2\%), Esfahan (67.5\%), Kermanshah (50.6\%), and Zanjan (58.09\%) provinces, Iran, demonstrated a lower rate of infection (24, 30). Ghorbani et al. reported that immunity status against HAV among Iranian military draftees in Tehran was 97.63\% in 2007 (31). Moreover, in 2016, Izadi et al. showed that the seroprevalence of HAV antibodies in Iranian soldiers in Tehran was $80.3 \%$ (22). By the selection of first-month soldiers at military service, the aforementioned studies showed the HAV prevalence of various provinces of Iran based on the hometown of soldiers. The epidemiology of this disease has changed over time in several areas.

In line with the results of some previous studies that male subjects were observed to have a significantly higher seroprevalence than female subjects, the current study also observed a significantly higher seropositivity rate in male participants. Regarding gender, various studies have shown different results, reporting no significant difference $(17,32-34)$ or some female cases $(24,27,35)$ and some male cases more prone to $\operatorname{HAV}(19,24)$. The inconsistent findings of the aforementioned studies might be due to the differences in methods and selected populations.

The individuals residing along the borders of Iran had less access to the standard drinking water; individu- als with a weak socioeconomic status and a member of crowded families had the most probability of seropositivity of HBV (19). In terms of family size, the results of the present study are consistent with the results of previous studies, which indicated that a high family dimension results in more immunity in comparison to less populated ones (19). The evidence has shown that overcrowding leads to the transmission of infectious respiratory, skin, and intestinal diseases, hepatitis A $(36,37)$, and psychological problems (38). Although the total fertility rates of Iranian couples had dropped below-replacement fertility (39), Sistan and Baluchistan had the highest birth rate result in having crowded families (40). Despite the low socioeconomic status, they want more children since the children have to work to support the family.

During the past decades, numerous countries in Asia have been enhanced in socioeconomic status associated with urbanization, health education, lifestyle, and access to improved food and water hygiene $(41,42)$. This pattern might reduce the population's immunity; therefore, more individuals remained susceptible to HAV infection. However, compared to that reported for previous studies, less seroprevalence was observed, which might have been caused by improvements in food and water hygiene (42). It is observed that higher levels of education and employment would result in a better socioeconomic status and an increase in quality of life and hygiene, leading to a lower likelihood of exposure to HAV. However, the results of the present study showed no significant difference between the HAV seroprevalence rates related to the place of residence (i.e., urban and rural). One possible explanation is the small sample size of the present study. It is similar to the current findings reported from Fars (43), Hormozgan (34), and Golestan (32) provinces and a report from Babol (33) that showed the seroprevalence rates of HAV were not statistically different between urban and rural residents. The present study examined the seropositivity of HAV in educational and employment status, and in line with results of previous studies, uneducated and unemployed parents had HAV seropositive children (15).

The present study had a limitation. Due to the difficulty of sample finding as a result of specific sociocultural problems in this province, it was required to use available sampling of the general population referring to laboratory services to undergo the tests before marriage. Given the prevalence of substance abuse, most individuals did not agree to participate in the study and did not allow for blood sampling. Therefore, it is suggested to perform studies with larger sample sizes on subjects to determine high-risk groups, such as health providers and medical students who are at enhanced risk for HAV infection due to occupational exposure in health care settings in Sistan and 


\begin{tabular}{|c|c|c|c|}
\hline \multirow{2}{*}{ Variables } & \multicolumn{2}{|c|}{ Anti-HAV Antibody } & \multirow{2}{*}{ P-Value } \\
\hline & Negative & Positive & \\
\hline \multicolumn{4}{|l|}{ Gender } \\
\hline Male & $5(4)$ & $120(96)$ & $0.007^{* *}$ \\
\hline Female & $17(13.6)$ & $108(86.4)$ & \\
\hline Number of family members (mean \pm SD) & $5.00 \pm 1.90$ & $6.32 \pm 1.74$ & $0.001^{* * *}$ \\
\hline \multicolumn{4}{|l|}{ Place of residence } \\
\hline Urban & $21(10)$ & $188(90)$ & 0.073 \\
\hline Rural & $1(2.4)$ & $40(97.6)$ & \\
\hline \multicolumn{4}{|l|}{ History of jaundice before the age of 12 years } \\
\hline Yes & 0 & $103(45.2)$ & $<0.001^{* * *}$ \\
\hline No & $22(100)$ & $125(54.8)$ & \\
\hline
\end{tabular}

Abbreviations: HAV, hepatitis A virus; SD, standard deviation.

${ }^{\text {a }}$ Values are expressed as No. (\%) unless otherwise indicated.

\begin{tabular}{|c|c|c|c|}
\hline \multirow{2}{*}{ Variables } & \multicolumn{2}{|c|}{ Anti-HAV Antibody } & \multirow{2}{*}{ P-Value } \\
\hline & Negative & Positive & \\
\hline Father's education & & & $<0.001^{* * *}$ \\
\hline Uneducated & 0 & $5(2.1)$ & \\
\hline Preliminary & 0 & $20(8.8)$ & \\
\hline Diploma & $2(9.1)$ & $103(45.2)$ & \\
\hline Bachelor's degree & $15(68.2)$ & $88(38.6)$ & \\
\hline Master's degree and higher & $5(22.7)$ & $12(5.3)$ & \\
\hline Mother's education & & & $<0.001^{* * *}$ \\
\hline Uneducated & $1(4.5)$ & $28(12.3)$ & \\
\hline Preliminary & 0 & $81(35.6)$ & \\
\hline Diploma & $8(36.4)$ & $86(37.7)$ & \\
\hline Bachelor's degree & $11(50)$ & $32(14)$ & \\
\hline Master's degree and higher & $2(9.1)$ & $1(0.4)$ & \\
\hline Father's occupation & & & 0.622 \\
\hline Unemployed & 0 & $3(1.3)$ & \\
\hline Worker & 0 & $8(3.5)$ & \\
\hline Governmental & $17(77.3)$ & $150(65.8)$ & \\
\hline Self-employed & $5(22.3)$ & $67(29.4)$ & \\
\hline Mother's occupation & & & $0.026^{*}$ \\
\hline Household & 0 & $3(1.33)$ & \\
\hline Worker & $11(50)$ & $57(25)$ & \\
\hline Governmental & $10(45.5)$ & $166(72.8)$ & \\
\hline Self-employed & $1(4.5)$ & $2(0.87)$ & \\
\hline
\end{tabular}

Abbreviation: HAV, hepatitis A virus. 
Baluchistan.

\subsection{Conclusion}

It can also be concluded that the seropositivity of HAV is high in both the urban and rural areas of Zahedan, Iran. Therefore, the HAV vaccination of the general population is not necessary. It is recommended to monitor HAV seroprevalence in the general population to determine highrisk groups, including anti-HAV seronegative individuals, for HAV vaccination in the residents of the southeast border.

\section{Acknowledgments}

The authors would like to express their gratitude to the participants for their contributions.

\section{Footnotes}

Authors' Contribution: All the authors had equal roles in performing the study and contributed to writing the paper.

Conflict of Interests: The authors declare that they have no conflict of interest.

Ethical Approval: The present study was carried out in accordance with the Declaration of Helsinki and the Ethical Guidelines for Medical and Health Research established by the Ministry of Health and Medical Education and Ministry of Science, Research and Technology, Iran. The approval was obtained from the Ethics Review Committee of Zahedan University of Medical Sciences (registration no.: IR.ZAUMS.REC.1393.7111).

Funding/Support: The current study was funded by a specific project grant from Zahedan University of Medical Sciences (grant No.: 7111).

Informed Consent: Written informed consent was received from the participants, which contained the wellexplained process and objectives of the study. All the participants with a minimum age of 18 years were included when signing the informed consent.

\section{References}

1. Previsani N, Lavanchy D, Siegl G. Hepatitis A. In: Mushawar IK, editor. Viral Hepatitis: Molecular Biology, Diagnosis, Epidemiology and Control. 10. Amsterdam: Elsevier; 2003. p. 1-30. doi: 10.1016/s01687069(03)10001-8.

2. Jefferies M, Rauff B, Rashid H, Lam T, Rafiq S. Update on global epidemiology of viral hepatitis and preventive strategies. World $J$ Clin Cases. 2018;6(13):589-99. doi: 10.12998/wjcc.v6.i13.589. [PubMed: 30430114]. [PubMed Central: PMC6232563].
3. Liu Z, Shi O, Zhang T, Jin L, Chen X. Disease burden of viral hepatitis A, B, C and E: A systematic analysis.JViral Hepat. 2020;27(12):1284-96. doi: 10.1111/jvh.13371. [PubMed: 32741034].

4. Ramezani A, Aghasadeghi MR, Mamishi S, Sabeti S, Bidari-Zerehpoosh F, Banifazl M, et al. Seroprevalence of Hepatitis A among Children and Young Adults Residing in Tehran, Iran: Implication for HAV Vaccination. Hepat Mon. 2018;18(4). doi:10.5812/hepatmon.66915.

5. Jonas MM. Hepatitis A virus infection: progress made, more work to be done. J Pediatr (Rio J). 2011;87(3):185-6. doi: 10.2223/JPED.2106. [PubMed: 21660374].

6. Ajelli M, Merler S. An individual-based model of hepatitis A transmission. J Theor Biol. 2009;259(3):478-88. doi: 10.1016/j.jtbi.2009.03.038. [PubMed: 19361529].

7. Abutaleb A, Kottilil S. Hepatitis A: Epidemiology, Natural History, Unusual Clinical Manifestations, and Prevention. Gastroenterol Clin North Am. 2020;49(2):191-9. doi: 10.1016/j.gtc.2020.01.002. [PubMed: 32389358]. [PubMed Central: PMC7883407].

8. Aggarwal R, Goel A. Hepatitis A: Epidemiology in resourcepoor countries. Curr Opin Infect Dis. 2015;28(5):488-96. doi: 10.1097/QCO.0000000000000188. [PubMed: 26203853].

9. Franco E, Meleleo C, Serino L, Sorbara D, Zaratti L. Hepatitis A: Epidemiology and prevention in developing countries. World J Hepatol. 2012;4(3):68-73. doi: 10.4254/wjh.v4.i3.68. [PubMed: 22489258]. [PubMed Central: PMC3321492].

10. Yamamoto C, Ko K, Nagashima S, Harakawa T, Fujii T, Ohisa M, et al. Very low prevalence of anti-HAV in Japan: High potential for future outbreak. Sci Rep. 2019;9(1):1493. doi: 10.1038/s41598-018-37349-1. [PubMed: 30728377]. [PubMed Central: PMC6365493].

11. Michaelis K, Poethko-Muller C, Kuhnert R, Stark K, Faber M. Hepatitis $A$ virus infections, immunisations and demographic determinants in children and adolescents, Germany. Sci Rep. 2018;8(1):16696. doi: 10.1038/s41598-018-34927-1. [PubMed: 30420608]. [PubMed Central: PMC6232152].

12. Jacobsen $\mathrm{KH}$, Wiersma ST. Hepatitis A virus seroprevalence by age and world region, 1990 and 2005. Vaccine. 2010;28(41):6653-7. doi: 10.1016/j.vaccine.2010.08.037. [PubMed: 20723630].

13. Merat S, Rezvan H, Nouraie M, Abolghasemi H, Jamali R, AminiKafiabad S, et al. Seroprevalence and risk factors of hepatitis A virus infection in Iran: A population based study. Arch Iran Med. 2010;13(2):99104. [PubMed: 20187662].

14. Taghavi SA, Hosseini Asl MK, Talebzadeh M, Eshraghian A. Seroprevalence study of hepatitis A virus in Fars province, southern Iran. Hepat Mon. 2011;11(4):285-8. [PubMed: 22706273]. [PubMed Central: PMC3206696].

15. Karimi A, Imani-Rastabi R, Moezzi M, Moradi M. Hepatitis A Seroprevalence and Associated Risk Factors: A Community-based Crosssectional Study in Shahrekord, Iran. Arch Clin Infect Dis. 2016;11(1). e32288. doi: 10.5812/archcid.32288.

16. Sadinejad M, Kelishadi R, Qorbani M, Shahsanai A, Motlagh ME, Ardalan G, et al. A Nationwide Survey on Some Hygienic Behaviors of Iranian Children and Adolescents: The CASPIAN-IV Study. Int J Prev Med. 2014;5(9):1083-90. [PubMed: 25317289]. [PubMed Central: PMC4192768].

17. Hoseini SG, Kelishadi R, Ataei B, Yaran M, Motlagh ME, Ardalan G, et al. Seroprevalence of hepatitis A in Iranian adolescents: Is it time to introduce a vaccine? Epidemiol Infect. 2016;144(2):291-6. doi: 10.1017/S0950268815001302. [PubMed: 26083105].

18. Farajzadegan Z, Hoseini SG, Kelishadi R, Jamshidi F, Nokhodian Z, Noori R, et al. Systematic review and meta-analysis on the age-specific seroprevalence of hepatitis A in Iran. J Res Med Sci. 2014;19(Suppl 1):S56-63. [PubMed: 25002897]. [PubMed Central: PMC4078371].

19. Lankarani KB, Honarvar B, Molavi Vardanjani H, Kharmandar A, Gouya MM, Zahraei SM, et al. Immunity to Hepatitis-A virus: A nationwide population-based seroprevalence study from Iran. Vaccine. 2020;38(45):7100-7. doi: 10.1016/j.vaccine.2020.08.071. [PubMed: 32917416]. 
20. World Health Organization. WHO position paper on hepatitis A vaccines - June 2012. Wkly Epidemiol Rec. 2012;87(28/29):261-76. [PubMed: 22905367].

21. Poureslami IM, MacLean DR, Spiegel J, Yassi A. Sociocultural, environmental, and health challenges facing women and children living near the borders between Afghanistan, Iran, and Pakistan (AIP region). MedGenMed. 2004;6(3):51. [PubMed: 15520675]. [PubMed Central: PMC1435647].

22. Izadi M, Esfahani AA, Hassannia H, Jonaidi Jafari N, Rahmati Najarkolaei F, Rezaee-Zavareh MS. Seroprevalence of hepatitis A virus among Iranian soldiers. Gastroenterol Hepatol Bed Bench. 2016;9(2):100-4. [PubMed: 27099669]. [PubMed Central: PMC4833848].

23. Shamsizadeh HDA, Mak VM. [Surveys of Hepatitis a Virus Immunity Among Children Aged 10-15 Years in Ahwaz City by Elisa Method]. Jundishapur Scientific Medical Journal. 2005;(44):21-6. Persian.

24. Vakili B, Rahimi H, Ataei B, Janghorbani M, Khorvash F, Shoaei P, et al. Hepatitis A seropositivity among newly admitted medical students of Isfahan, Kermanshah, and Hamedan: A seroprevalence study.J Res Med Sci. 2014;19(Suppl 1):S9-S12. [PubMed: 25002901]. [PubMed Central: PMC4078374].

25. Ramezani H, Bozorgi SH, Nooranipour M, Mostajeri A, Kargar-Fard $\mathrm{H}$, Molaverdikhani S, et al. Prevalence and risk factors of hepatitis A among blood donors in Qazvin, central Iran. Singapore Med J. 2011;52(2):107-12. [PubMed: 21373737].

26. Miri R, Ahmadi Ghezeldasht S, Hedayati-Moghadam MR, Fathimoghadam F, Bidkhori H, Shamsian SA, et al. Seropositivity of Antibodies Against Hepatitis A Virus in Mashhad, Northeast of Iran: A Cross-Sectional Community-Based Study During 2009. Razavi Int J Med. 2015;3(2). e27082. doi:10.5812/rijm.3(2)2015.27082.

27. Alian S, Ajami A, Ghasemian R, Yadegarinia D. Age-specific seroprevalence of hepatitis A in Sari, northern Islamic Republic of Iran. East Mediterr Health J. 2011;17(10):754-8. doi: 10.26719/2011.17.10.754. [PubMed: 22256409].

28. Salehi M. [Seroepidemiology of hepatitis A in population under 30 years old in rural area of Zabol]. Journal of Guilan University of Medical Sciences. 2001;10(37):26-9. Persian.

29. Ayatollahi J, Hadinadoshan H. [Evaluation of anti-HAV antibody in secondary school students of Yazd city]. Shahid Sadoughi Univ Med. 2001;9(4):87-90. Persian.

30. Asaei S, Ziyaeyan M, Moeini M, Jamalidoust M, Behzadi MA. Seroprevalence of Hepatitis A and E Virus Infections Among Healthy Population in Shiraz, Southern Iran. Jundishapur J Microbiol. 2015;8(7). e19311. doi: 10.5812/jjm.19311v2. [PubMed: 26421130]. [PubMed Central: PMC4584134].

31. Ghorbani G, Alavian S, Asaari S. Seroepidemiology of hepatitis A virus in Iranian soldiers in 2006: do they need vaccination? Hepat Mon. 2007;7(1):7-9.
32. Abdolvahab M, Behnaz K, Sima B, M T. Hepatitis a in young adults in the golestan province, northeast of iran. J Glob Infect Dis. 2010;2(2):198-9. doi: 10.4103/0974-777X.62862. [PubMed: 20606982]. [PubMed Central: PMC2889666].

33. Roushan MR, Bijani A, Sagheb R, Jazayeri O. Prevalence of hepatitis A IgG in individuals with chronic hepatitis B infection in Babol. East Mediterr Health J. 2007;13(5):1108-13. doi: 10.26719/2007.13.5.1108. [PubMed: 18290404].

34. Behzadi MA, Leyva-Grado VH, Namayandeh M, Ziyaeyan A, Feyznezhad R, Dorzaban H, et al. Seroprevalence of viral hepatitis $A, B, C, D$ and $E$ viruses in the Hormozgan province southern Iran. BMC Infect Dis. 2019;19(1):1027. doi: 10.1186/s12879-019-4661-4. [PubMed: 31795979]. [PubMed Central: PMC6889522].

35. Ehsanipour F, Shayanfar N, Azimi M. [Seroprevalence of Hepatitis A infection in children referred to Rasoul Akram Hospital]. Razi Journal of Medical Sciences (Journal of Iran University of Medical Sciences). 2006;13(51):25-31. Persian.

36. Baker MG, McDonald A, Zhang J, Howden-Chapman P. Infectious diseases attributable to household crowding in New Zealand: A systematic review and burden of disease estimate. Wellington South, New Zealand: Wellington: He Kainga Oranga/Housing and Health Research; 2013.

37. Altinkaynak S, Selimoglu MA, Ertekin V, Kilicaslan B. Epidemiological factors affecting hepatitis a seroprevalence in childhood in a developing country. Eurasian J Med. 2008;40(1):25-8. [PubMed: 25610018]. [PubMed Central: PMC4261326].

38. Evans GW, Saegert S, Harris R. Residential Density and Psychological Health among Children in Low-Income Families. Environ Behav. 2016;33(2):165-80. doi: 10.1177/00139160121972936.

39. Mehri N, Messkoub M, Kunkel S. Trends, Determinants and the Implications of Population Aging in Iran. Ageing Int. 2020;45(4):327-43. doi: 10.1007/s12126-020-09364-z.

40. Sargolzaie N, Kiani M, Dehghan Haghighi J, Sargazi S. Determinants of Fertility Patterns in Zahedan, Southeast Iran, 2015. Health Scope. 2016;6(3). e15117. doi: 10.5812/jhealthscope.15117.

41. Wong MCS, Huang JLW, George J, Huang J, Leung C, Eslam M, et al. The changing epidemiology of liver diseases in the Asia-Pacific region. Nat Rev Gastroenterol Hepatol. 2019;16(1):57-73. doi: 10.1038/s41575-0180055-0. [PubMed: 30158570].

42. Jacobsen KH. Globalization and the Changing Epidemiology of Hepatitis A Virus. Cold Spring Harb Perspect Med. 2018;8(10). doi: 10.1101/cshperspect.a031716. [PubMed: 29500305]. [PubMed Central: PMC6169986].

43. Saffar MJ, Abedian O, Ajami A, Abedian F, Mirabi AM, Khalilian AR, et al. Age-specific seroprevalence of anti-hepatitis a antibody among 1-30 years old population of savadkuh, mazandaran, iran with literature review. Hepat Mon. 2012;12(5):326-32. doi: 10.5812/hepatmon.6035. [PubMed: 22783344]. [PubMed Central: PMC3389358]. 